\title{
ClC-2 Channels Regulate Neuronal Excitability, Not Intracellular Chloride Levels
}

\author{
Stéphanie Ratté and Steven A. Prescott \\ Department of Neurobiology and the Pittsburgh Center for Pain Research, University of Pittsburgh, Pittsburgh, Pennsylvania 15213
}

\begin{abstract}
Synaptic inhibition by $\mathrm{GABA}_{\mathrm{A}}$ receptors requires a transmembrane chloride gradient. Hyperpolarization or shunting results from outward current produced by chloride flowing down this gradient, into the cell. Chloride influx necessarily depletes the chloride gradient. Therefore, mechanisms that replenish the gradient (by reducing intracellular chloride concentration, $\left[\mathrm{Cl}^{-}\right]_{\mathrm{i}}$ ) are crucial for maintaining the efficacy of $\mathrm{GABA}_{\mathrm{A}}$ receptor-mediated inhibition. $\mathrm{ClC}-2$ is an inward-rectifying chloride channel that is thought to help extrude chloride because inward rectification should, in principle, allow ClC-2 to act as a one-way chloride exit valve. But chloride efflux via ClC-2 nevertheless requires an appropriate driving force. Using computer modeling, we reproduced voltage-clamp experiments showing chloride efflux via ClC-2, but testing the same model under physiological conditions revealed that ClC-2 normally leaks chloride into the cell. The discrepancy is explained by the driving force conditions that exist under artificial versus physiological conditions, and by the fact that ClC-2 rectification is neither complete nor instantaneous. Thus, contrary to previous assertions that $\mathrm{ClC}-2$ helps maintain synaptic inhibition by lowering $\left[\mathrm{Cl}^{-}\right]_{\mathrm{i}}$, our simulations show that ClC-2 mediates chloride influx, thus producing outward current and directly reducing excitability. To test how ClC-2 functions in real neurons, we used dynamic clamp to insert virtual ClC-2 channels into rat CA1 pyramidal cells with and without native ClC-2 channels blocked. Experiments confirmed that ClC-2 reduces spiking independently of inhibitory synaptic transmission. Our results highlight the importance of considering driving force when inferring how a channel functions under physiological conditions.
\end{abstract}

\section{Introduction}

Fast synaptic inhibition is mediated predominantly by $\mathrm{GABA}_{\mathrm{A}}$ receptors $\left(\mathrm{GABA}_{\mathrm{A}} \mathrm{Rs}\right)$ that cause hyperpolarization or prevent (i.e., shunt) depolarization by producing outward current via $\mathrm{Cl}^{-}$influx. This requires an appropriate driving force, i.e., $E_{\mathrm{Cl}}$ must be more negative than $V$. Whenever $\mathrm{Cl}^{-}$influx occurs, the transmembrane $\mathrm{Cl}^{-}$gradient is depleted. The $\mathrm{Cl}^{-}$gradient must therefore be continually replenished for synaptic inhibition to remain effective. Strong $\mathrm{Cl}^{-}$influx through $\mathrm{GABA}_{\mathrm{A}} \mathrm{R}$ can transiently overwhelm $\mathrm{Cl}^{-}$extrusion mechanisms (Thompson and Gahwiler, 1989; Staley et al., 1995; Staley and Proctor, 1999), and pathological reduction of $\mathrm{Cl}^{-}$extrusion capacity can cause depolarizing shifts in baseline $E_{\mathrm{Cl}}$ (for review, see De Koninck, 2007; Kahle et al., 2008). Understanding the strength and robustness of synaptic inhibition requires that we understand how the transmembrane $\mathrm{Cl}^{-}$gradient is maintained.

Maintaining low $\left[\mathrm{Cl}^{-}\right]_{\mathrm{i}}$ in neurons of the adult CNS is typically attributed to the $\mathrm{K}^{+}-\mathrm{Cl}^{-}$cotransporter $\mathrm{KCC} 2$, which harnesses the transmembrane $\mathrm{K}^{+}$gradient to extrude $\mathrm{Cl}^{-}$via an electroneutral cotransport process (for review, see Payne et al.,

\footnotetext{
Received June 2, 2011; revised Sept. 20, 2011; accepted Sept. 21, 2011.

Author contributions: S.R. and S.A.P. designed research; S.R. and S.A.P. performed research; S.R. and S.A.P. analyzed data; S.R. and S.A.P. wrote the paper.

This work was supported by a Rita Allen Foundation Scholar in Pain Award and a Mallinckrodt Scholar Award to S.A.P. We thank John Horn for comments on this manuscript.

Correspondence should be addressed to Steven A. Prescott, Department of Neurobiology, University of Pittsburgh, W1455 Biomedical Science Tower, 200 Lothrop Street, Pittsburgh, PA 15213. E-mail: prescott@ neurobio.pitt.edu.

DOI:10.1523/JNEUROSCI.2748-11.2011

Copyright $\odot 2011$ the authors $\quad 0270-6474 / 11 / 315838-06 \$ 15.00 / 0$
}

2003; Blaesse et al., 2009). Other cotransporters and exchangers may contribute to maintaining low $\left[\mathrm{Cl}^{-}\right]_{\mathrm{i}}$, but ion channels are typically ill suited for this purpose because, when open, they let ions run down their gradients. Despite this, the voltage- and chloride-sensitive channel ClC-2 has been proposed to help regulate $\left[\mathrm{Cl}^{-}\right]_{\mathrm{i}}$ because inward rectification should, in principal, cause it to act as one-way $\mathrm{Cl}^{-}$exit valve (Staley, 1994; Földy et al., 2010; Rinke et al., 2010; Smart, 2010). Chloride efflux via $\mathrm{ClC}-2$ nevertheless requires an appropriate driving force; specifically, $E_{\mathrm{Cl}}$ must be less negative than (i.e., depolarized relative to) $V$. Those conditions exist when $V$ is manipulated directly by voltage-clamp and high- $\mathrm{Cl}^{-}$pipette solutions and/or KCC2 blockade render $E_{\mathrm{Cl}}$ unnaturally depolarized, but tend not to occur under physiological conditions. Driving force normally promotes $\mathrm{Cl}^{-}$influx, which means an imperfect exit valve could leak $\mathrm{Cl}^{-}$into the cell. Indeed, experiments have suggested that ClC-2 reduces excitability by contributing to leak conductance (Madison et al., 1986; Rinke et al., 2010). Whether ClC-2 regulates $\left[\mathrm{Cl}^{-}\right]_{\mathrm{i}}$ under physiological conditions, and if not, what its true physiological role is, are important yet unresolved issues.

To resolve these issues, we built a computational model that tracks $V$ and $\left[\mathrm{Cl}^{-}\right]_{\mathrm{i}}$ using ClC-2 parameters characterized in CA1 pyramidal cells (Staley, 1994). After validating our model by comparison against past voltage-clamp experiments, we tested it under physiological conditions (i.e., in current clamp, without pipette dialysis, with KCC2 intact). Contrary to voltage-clamp simulations, current-clamp simulations showed that $\mathrm{ClC}-2$ usually leaks $\mathrm{Cl}^{-}$into the cell, thus producing outward current that directly reduces excitability. We confirmed these results experimentally by using dynamic clamp to insert virtual $\mathrm{ClC}-2$ 
current into CA1 pyramidal cells. Our results argue that ClC-2 reduces excitability directly rather than by regulating $\left[\mathrm{Cl}^{-}\right]_{\mathrm{i}}$ for the benefit of synaptic inhibition.

\section{Materials and Methods}

Computer simulations. Simulations were conducted using a singlecompartment Morris-Lecar model (Prescott et al., 2008) to which adaptation, $\mathrm{ClC}-2$, and synaptic conductances were added.

$$
\begin{gathered}
C d V / d t=-\bar{g}_{\mathrm{Na}} m_{\infty}(V)\left(V-E_{\mathrm{Na}}\right)-\bar{g}_{\mathrm{K}} w\left(V-E_{\mathrm{K}}\right)-g_{\text {leak }}\left(V-E_{\text {leak }}\right) \\
-\bar{g}_{\text {adapt }} z\left(V-E_{\mathrm{K}}\right)-g_{\text {exc }}(t)\left(V-E_{\mathrm{exc}}\right)-g_{\text {inh }}(t)\left(V-E_{\mathrm{GABA}}\right) \\
d w / d t=\phi_{w} \frac{w_{\infty}(V)-w}{\tau_{w}(V)} \\
d z / d t=\frac{z_{\infty}(V)-z}{\tau_{z}} \\
d p / d t=\frac{p_{\infty}(V)-p}{\tau_{p}} \\
m_{\infty}(V)=0.5\left[1+\tanh \left(\frac{V-\beta_{m}}{\gamma_{m}}\right)\right] \\
p_{\infty}(V)=\frac{1}{1+\exp \left(\frac{E_{\mathrm{Cl}}-V_{\text {half }}-V}{V_{\text {slope }}}\right)} \\
w_{\infty}(V)=0.5\left[1+\tanh \left(\frac{V-\beta_{w}}{\gamma_{w}}\right)\right] \\
\tau_{w}(V)=1 / \cosh \left(\frac{V-\beta_{w}}{2 \cdot \gamma_{w}}\right) \\
1
\end{gathered}
$$

where $V$ is voltage and $m, w, z$, and $p$ are gating variables controlling activation of $g_{\mathrm{Na}}, g_{\mathrm{K}}, g_{\text {adapt }}$, and $g_{\mathrm{ClC} 2}$, respectively; $m$ changes instantaneously with $V$, whereas $w, z$, and $p$ evolve according to time constants $\tau_{w}, \tau_{z}$ and $\tau_{p}$. Fast $\mathrm{Na}^{+}$conductance $\bar{g}_{\mathrm{Na}}=20 \mathrm{mS} / \mathrm{cm}^{2}$, delayedrectifier $\mathrm{K}^{+}$conductance $\bar{g}_{\mathrm{K}}=20 \mathrm{mS} / \mathrm{cm}^{2}$, and nonspecific leak conductance $g_{\text {leak }}=1 \mathrm{mS} / \mathrm{cm}^{2}$. Adaptation was included only in simulations in Figure 3, $B$ and $C$, where $\bar{g}_{\text {adapt }}=3 \mathrm{mS} / \mathrm{cm}^{2}$. Excitatory and inhibitory synaptic conductances $g_{\text {exc }}$ and $g_{\text {inh }}$ and ClC-2 conductance $g_{\mathrm{ClC}_{\mathrm{C} 2}}$ are reported in Results. Other parameters were $C=2$ $\mu \mathrm{F} / \mathrm{cm}^{2}, \beta_{m}=-1.2 \mathrm{mV}, \gamma_{m}=18 \mathrm{mV}, \beta_{w}=-9 \mathrm{mV}, \gamma_{w}=10 \mathrm{mV}, \phi_{w}$ $=0.25, \beta_{z}=0 \mathrm{mV}, \gamma_{z}=5 \mathrm{mV}$, and $\tau_{z}=100 \mathrm{~ms}$. Activation parameters for ClC-2 were based on Staley (1994): $V_{\text {half }}=15 \mathrm{mV}, V_{\text {slope }}=$ $-14 \mathrm{mV}$, and $\tau_{p}=300 \mathrm{~ms}\left(=\tau_{\mathrm{ClC} 2}\right)$. Reversal potentials were $E_{\text {Leak }}=$ $-70 \mathrm{mV}, E_{\mathrm{Na}}=+45 \mathrm{mV}, E_{\mathrm{K}}=-90 \mathrm{mV}$, and $E_{\mathrm{exc}}=0 \mathrm{mV}$.

GABA reversal potential $E_{\mathrm{GABA}}$ must account for $\mathrm{Cl}^{-}$and $\mathrm{HCO}_{3}^{-}$flux through $\mathrm{GABA}_{\mathrm{A}}$ channels and was calculated by the Goldman-Hodgkin-Katz equation:

$$
E_{\mathrm{GABA}}=10^{3} \frac{R T}{F} \ln \left(\frac{4\left[\mathrm{CI}^{-}\right]_{\mathrm{i}}+\left[\mathrm{HCO}_{3}^{-}\right]_{\mathrm{i}}}{4\left[\mathrm{CI}^{-}\right]_{0}+\left[\mathrm{HCO}_{3}^{-}\right]_{0}}\right)
$$

where $R=8.3 \mathrm{~J} \cdot \mathrm{mol}^{-1} \cdot \mathrm{K}^{-1}, T=310 \mathrm{~K}\left(37^{\circ} \mathrm{C}\right), F=96,485^{\circ} \mathrm{C} \cdot \mathrm{mol}^{-1}$, and $\mathrm{i}$ and o designate intracellular and extracellular concentrations. The 4:1 relative permeability to $\mathrm{Cl}^{-}$and $\mathrm{HCO}_{3}^{-}$is specified by the factor 4 . Intracel- lular and extracellular $\left[\mathrm{HCO}_{3}^{-}\right]$were assumed to remain constant at 11.8 and $25 \mathrm{~mm}$, respectively, since intracellular $\mathrm{HCO}_{3}^{-}$is replenished by conversion of $\mathrm{CO}_{2} ; E_{\mathrm{HCO}}$ therefore remains constant at $-20 \mathrm{mV}$ (as determined by the Nernst equation). Extracellular $\left[\mathrm{Cl}^{-}\right]$remained constant at $120 \mathrm{~mm}$, whereas $\left[\mathrm{Cl}^{-}\right]_{\mathrm{i}}$ was continuously updated according to

$$
\begin{gathered}
d\left[\mathrm{CI}^{-}\right]_{\mathrm{i}} / d t=\mathrm{SAV} \frac{g_{\mathrm{inh}} x\left(V-E_{\mathrm{Cl}}\right)+g_{\mathrm{KCC} 2}\left(E_{\mathrm{K}}-E_{\mathrm{Cl}}\right)}{+g_{\mathrm{C} 1 \mathrm{C} 2}\left(V-E_{\mathrm{Cl}}\right)} \\
F \quad+\frac{\left[\mathrm{CI}^{-}\right]_{\text {pip }}-\left[\mathrm{CI}^{-}\right]_{\mathrm{i}}}{\tau_{\text {pip }}},
\end{gathered}
$$

where the first term accounts for transmembrane $\mathrm{Cl}^{-}$flux and the second term (included only in voltage-clamp simulations) accounts for intracellular dialysis from the recording pipette; $\tau_{\text {pip }}=1 \mathrm{~s}$ and $\left[\mathrm{Cl}^{-}\right]_{\text {pip }}=$ $40 \mathrm{~mm}$ unless otherwise specified. Surface area to volume ratio is accounted for by SAV $=10^{-4} s / r$, where $s=3$ and $r=6.3 \mu \mathrm{m}$ for a spherical soma (surface area $=5 \times 10^{-6} \mathrm{~cm}^{2}$ ) and $s=2$ and $r=1 \mu \mathrm{m}$ for a cylindrical dendrite. For the somatic surface area, $\bar{g}_{\mathrm{ClC} 2}=1 \mathrm{mS} / \mathrm{cm}^{2}$ gives a total ClC-2 conductance of $5 \mathrm{nS}$, consistent with Staley (1994). The fraction of $\mathrm{GABA}_{\mathrm{A}}$ current attributable to $\mathrm{Cl}^{-}$flux (as opposed to $\mathrm{HCO}_{3}^{-}$ flux $)$ is calculated as $x=\left(E_{\mathrm{HCO} 3}-E_{\mathrm{GABA}}\right) /\left(E_{\mathrm{HCO} 3}-E_{\mathrm{Cl}}\right)$. Chloride reversal potential $E_{\mathrm{Cl}}$ was calculated from the Nernst equation. When KCC2 was included, $g_{\mathrm{KCC} 2}$ was set conservatively to $0.7 \mathrm{mS} / \mathrm{cm}^{2}$ (Doyon et al., 2011). Because cotransport is electroneutral (i.e., $\mathrm{Cl}^{-}$efflux is balanced by $\mathrm{K}^{+}$efflux), the term $g_{\mathrm{KCC} 2}\left(E_{\mathrm{K}}-E_{\mathrm{Cl}}\right)$ is included in Equation 11 but is absent from Equation 1. $\left[\mathrm{Cl}^{-}\right]_{\mathrm{i}}$ was assumed to be spatially homogeneous based on effects of intracellular diffusion (Doyon et al., 2011).

Unless otherwise indicated, $g_{\text {exc }}$ and $g_{\text {inh }}$ were turned on or off but otherwise remained constant. In some simulations, synaptic bombardment was simulated by varying $g_{\text {exc }}$ and $g_{\text {inh }}$ according to Ornstein-Uhlenbeck processes (Uhlenbeck and Ornstein, 1930; Prescott and De Koninck, 2009):

$$
d \zeta=-\frac{\zeta}{\tau} d t+N_{\tau} \xi(0,1) \sqrt{d t}
$$

where $\xi(0,1)$ is a random number with 0 mean and unit variance and $N_{\tau}$ is a scaling factor $\sqrt{2 / \tau}$ so that $\zeta(t)$ has unit variance. Synaptic conductance $g(t)=\mu+\sigma \zeta(t)$, where $\mu$ and $\sigma$ specify the mean and standard deviation, respectively, of the fluctuating conductance. Parameter values are reported in Results.

Equations were integrated in XPP (Ermentrout, 2002) using the Euler method with a time step of $0.05-0.1 \mathrm{~ms}$. Code will be available in ModelDB.

Electrophysiology. Experimental procedures were approved by the University of Pittsburgh Institutional Animal Care and Use Committee and have been described previously (Prescott et al., 2006). Hippocampal slices were prepared from adult male Sprague Dawley rats. Slices were transferred to a recording chamber perfused with oxygenated $\left(95 \% \mathrm{O}_{2}\right.$ and $5 \% \mathrm{CO}_{2}$ ) ACSF heated to $31 \pm 1{ }^{\circ} \mathrm{C}$. CA1 pyramidal neurons were recorded in whole-cell mode with $>70 \%$ series resistance compensation using an Axopatch 200B amplifier (Molecular Devices). Membrane potential (after correction for a liquid junction potential of $9 \mathrm{mV}$ ) was adjusted to $-70 \mathrm{mV}$ through tonic current injection. Intracellular recording solution contained (in mM) $125 \mathrm{KMeSO}_{4}, 5 \mathrm{KCl}, 10 \mathrm{HEPES}, 2$ $\mathrm{MgCl}_{2}, 4$ ATP (Sigma), 0.4 GTP (Sigma), and 0.1\% Lucifer yellow; pH was adjusted to 7.2 with $\mathrm{KOH}$. Using the Ornstein-Uhlenbeck processes described above, virtual synaptic conductances were injected using dynamic clamp (Signal 5, CED). $E_{\mathrm{GABA}}$ was fixed at $-60 \mathrm{mV}$, similar to $E_{\text {GABA }}$ values in high-conductance state simulations (see Fig. $3 C$ ). Neurons were given 10-s-long barrages of virtual synaptic input. Conductance fluctuation amplitude $(\sigma)$ was fixed at $1 \mathrm{nS}$ and $0.25 \mathrm{nS}$ for $g_{\text {exc }}$ and $g_{\text {inh }}$, respectively; the mean conductance $(\mu)$ was varied to achieve a range of firing rates. Spikes were counted over the last $9 \mathrm{~s}$ of each trial to exclude adaptation during the first second. In interleaved trials, virtual ClC-2 conductance was inserted via dynamic clamp. ClC-2 activation parameters were identical to simulations. We tested at least two $g_{\mathrm{ClC} 2}$ values per cell, and three levels overall. Simulations indicated that native 
and virtual $\mathrm{ClC}-2$ channels have additive effects on excitability (data not shown), but nevertheless, some dynamic clamp experiments were repeated after blockade of native $\mathrm{ClC}-2$ channels by $100 \mu \mathrm{M}$ zinc (Staley, 1994). To calculate the driving force for ClC-2, $E_{\mathrm{Cl}}$ was approximated as $-70 \mathrm{mV}$ based on simulation results in Figure 3C. Spike counts from trials with $\mathrm{ClC}-2$ were compared with spike counts from the immediately preceding trial without ClC-2, thereby comparing only responses to equivalent virtual synaptic input and avoiding the confounding influence of any slow drift in excitability. Responses were low-pass filtered at 2 $\mathrm{kHz}$ and digitized at $20 \mathrm{kHz}$ using a CED 1401 computer interface.

\section{Results}

\section{Model validation based on} voltage-clamp simulations

We began by validating our model through comparison with past voltageclamp experiments. Inward rectification was clearly evident from the ClC-2 $I-V$ curve measured from our model (Fig. $1 A)$; this replicates Figure $1 A$ of Staley (1994). To determine how ClC-2 affects steady-state $\left[\mathrm{Cl}^{-}\right]_{\mathrm{i}}$ assayed by the amplitude of $\mathrm{GABA}_{\mathrm{A}} \mathrm{R}$ responses, we clamped the model neuron at different $V$ and recorded $I_{\mathrm{GABA}}$ in response to 10 -ms-long activations of $g_{\text {inh }}$ (Fig. $1 B$, left panel); this replicates Figure $2 d$ of Földy et al. (2010). ClC-2-dependent reduction in inward $I_{\mathrm{GABA}}$ reflects the hyperpolarizing shift in $E_{\mathrm{Cl}}$ (Fig. $1 B$, top right panel) caused by $\mathrm{ClC}$-2-mediated inward current (i.e., $\mathrm{Cl}^{-}$ efflux) (Fig. $1 B$, bottom right panel) over the corresponding voltage range. To be clear, under the simulated conditions with $\left[\mathrm{Cl}^{-}\right]_{\text {pip }}=40 \mathrm{~mm},\left[\mathrm{Cl}^{-}\right]_{\mathrm{i}}$ is high (i.e., $E_{\mathrm{Cl}}$ is above $V_{m}$ ), which means $\mathrm{Cl}^{-}$ exits the cell via $G_{A B A} R$ when those channels are open; less $\mathrm{Cl}^{-}$exits through $\mathrm{GABA}_{\mathrm{A}} \mathrm{R}$ if some has already leaked out via $\mathrm{ClC}-2$. To determine how $\mathrm{ClC}-2$ affects the rate of $\mathrm{Cl}^{-}$extrusion, we loaded the model neuron with $\mathrm{Cl}^{-}$by clamping $V$ at $+60 \mathrm{mV}$ with $g_{\text {inh }}$ on, then $g_{\text {inh }}$ was turned off and $V_{\text {clamp }}$ was reset to -90 $\mathrm{mV}$. ClC-2 expedited $\mathrm{Cl}^{-}$clearance (Fig. $1 C)$; this replicates Figure $2 f$ of Földy et al. (2010) and Figure 2 of Rinke et al. (2010). To summarize, our model reproduced ClC-2 rectification properties (Staley, 1994) and the voltage-clamp data that are the basis for concluding that $\mathrm{ClC}-2$ contributes to intracellular $\mathrm{Cl}^{-}$homeostasis (Földy et al., 2010; Rinke et al., 2010).

Regulation of $\left[\mathrm{Cl}^{-}\right]_{\mathrm{i}}$ in mature central neurons is typically ascribed to KCC2 (see Introduction). Chloride extrusion by $\mathrm{ClC}-2$ and $\mathrm{KCC} 2$ are not mutually exclusive, but most previous experiments on $\mathrm{ClC}-2$ (Staley, 1994; Földy et al., 2010; Rinke et al., 2010) were con-
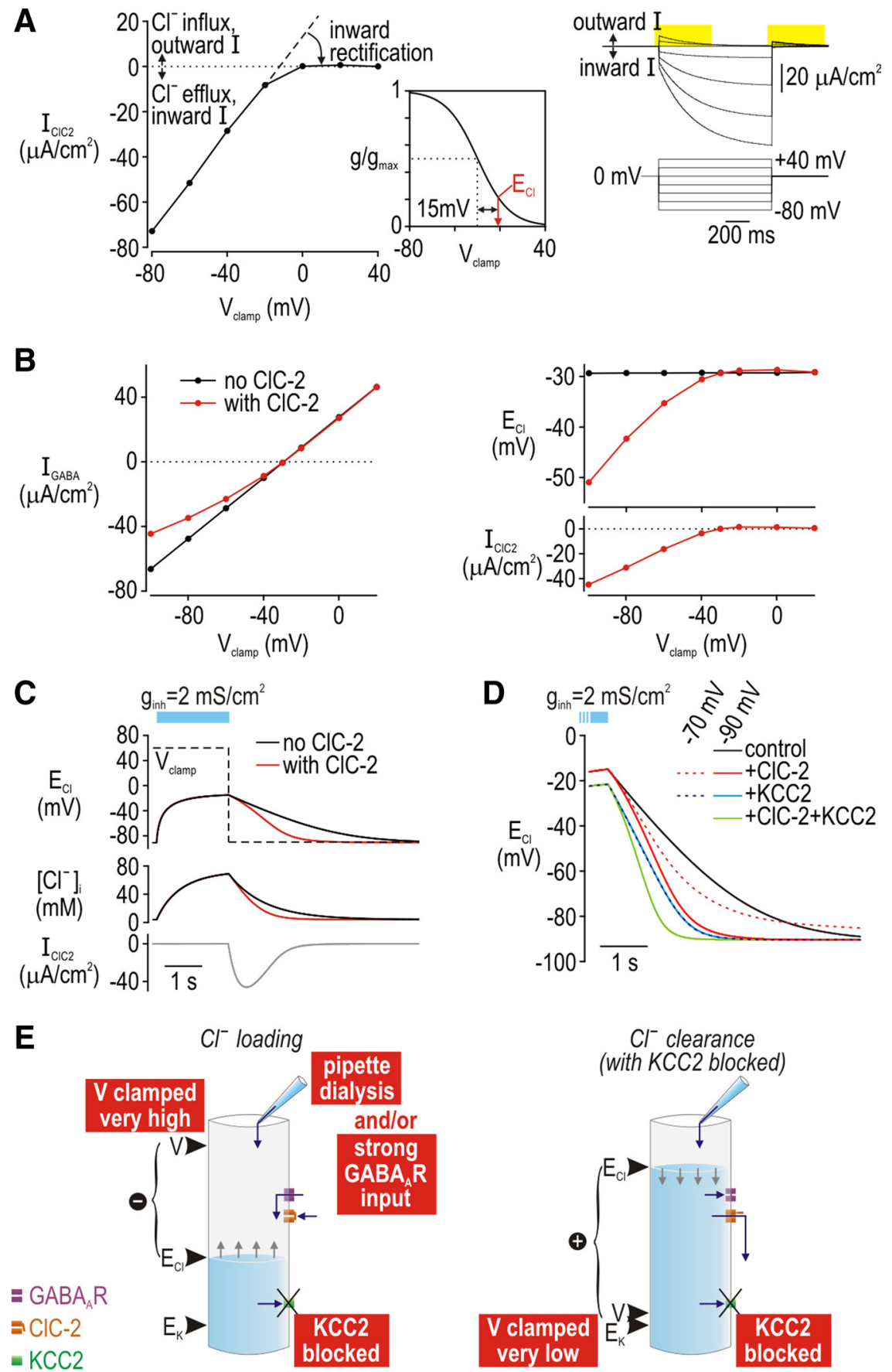

Figure 1. Reproduction of voltage-clamp data in model neuron. $A, \mathrm{ClC}-2$ current $\left(I_{\mathrm{CIC} 2}\right)$ was measured at the end of 1-s-long $V_{\text {clamp }}$ steps from $0 \mathrm{mV}$. Traces show responses to voltage-clamp protocol; yellow shading highlights outward $I_{\mathrm{CI} 2}$. Inset shows $\mathrm{CIC}-2$ activation. In $\boldsymbol{A},\left[\mathrm{Cl}^{-}\right]_{\mathrm{i}}$ was fixed at $100 \mathrm{~mm}$, giving $E_{\mathrm{Cl}}=-5 \mathrm{mV}$. In $\boldsymbol{B}-\boldsymbol{D},\left[\mathrm{Cl}^{-}\right]_{\mathrm{i}}$ was continuously updated according to Equation 11. KCC2 was not included in voltage-clamp simulations except where indicated in $\boldsymbol{D}$. $\boldsymbol{B}$, Impact of CIC-2 on $\mathrm{GABA}_{A} \mathrm{R}$ mediated current $\left(I_{\text {GABA }}\right)$ was measured at different $V_{\text {clamp }}$ by turning on $g_{\text {inh }}\left(1 \mathrm{mS} / \mathrm{cm}^{2}\right)$ for $10 \mathrm{~ms}$. Inward $I_{\text {GABA }}$ (left panel) was less in the model with $\mathrm{CIC}-2$ because inward $I_{\mathrm{CIC}}$ (bottom right panel) caused a hyperpolarizing shift in $E_{\mathrm{CI}}$ (top right panel) by reducing $\left[\mathrm{Cl}^{-}\right]_{\mathrm{i}}$. C, Rate of $\mathrm{Cl}^{-}$extrusion was evaluated by loading the model neuron with $\mathrm{Cl}^{-}$by turning on $g_{\text {inh }}$ (cyan bar) while $V_{\text {clamp }}=+60 \mathrm{mV}$, then monitoring recovery of $\left[\mathrm{Cl}^{-}\right]_{i}$ after $g_{\text {inh }}$ was turned off and $V_{\text {clamp }}$ was reset to $-90 \mathrm{mV}$. CIC-2 expedited $\mathrm{Cl}^{-}$removal. D, Simulations like in Cwere repeated with CIC-2 and/or KCC2, and with $V_{\text {clamp }}$ stepped to $-90 \mathrm{mV}$ or $-70 \mathrm{mV}$ after $\mathrm{Cl}^{-}$loading. Unlike $\mathrm{ClC}-2, \mathrm{KCC}_{2}$ mitigated $\mathrm{Cl}^{-}$accumulation and extruded $\mathrm{Cl}^{-}$equally well regardless of $V_{\text {clamp. }}, \boldsymbol{E}$, Summary of conditions under which $\mathrm{ClC}-2$ mediates $\mathrm{Cl}^{-}$efflux.

ducted with cesium in the pipette, which blocks KCC2 (Blaesse et al., 2009) and might thus overemphasize $\mathrm{Cl}^{-}$extrusion via $\mathrm{ClC}-2$. Therefore, we compared $\mathrm{Cl}^{-}$extrusion through different mechanisms and with different $V_{\text {clamp }}$ steps (Fig. 1D). Whereas $V_{\text {clamp }}$ af- 
A

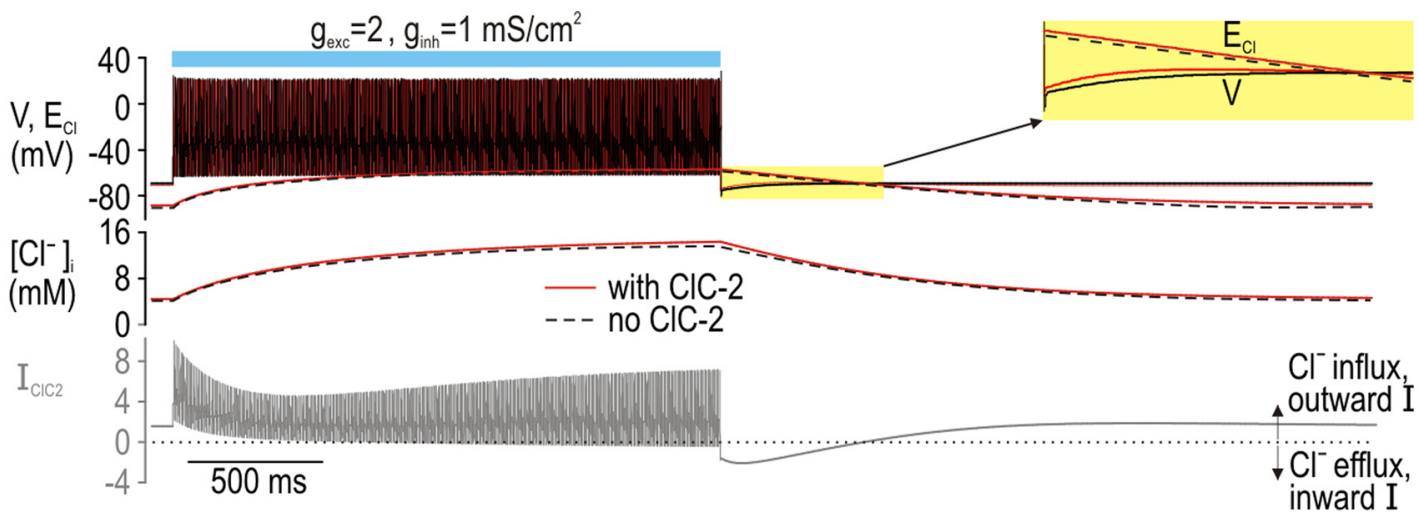

B

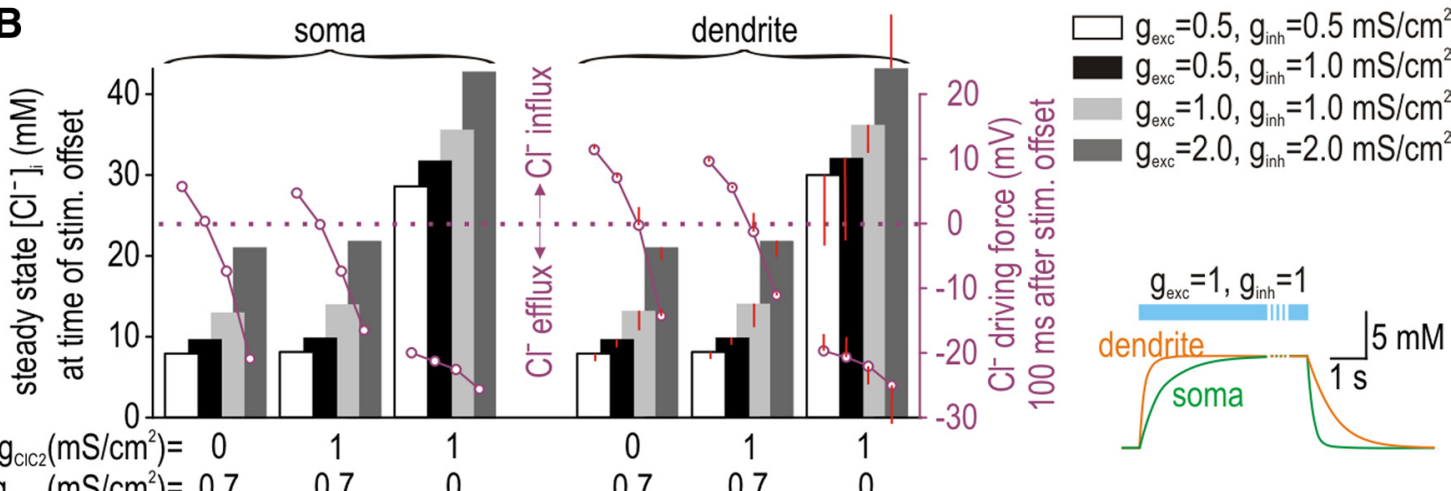
$\mathrm{g}_{\mathrm{kcc} 2}\left(\mathrm{mS} / \mathrm{cm}^{2}\right)=0.7$

$0.7 \quad 0$

$0.7 \quad 0.7$

0

C

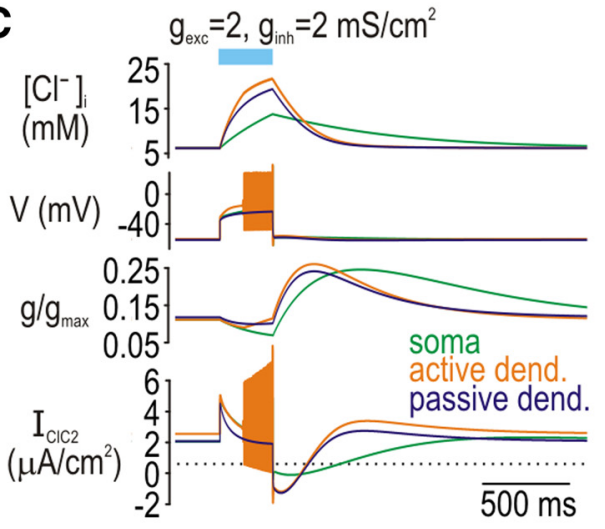

D $\tau_{\mathrm{clC2}}=300 \mathrm{~ms}$

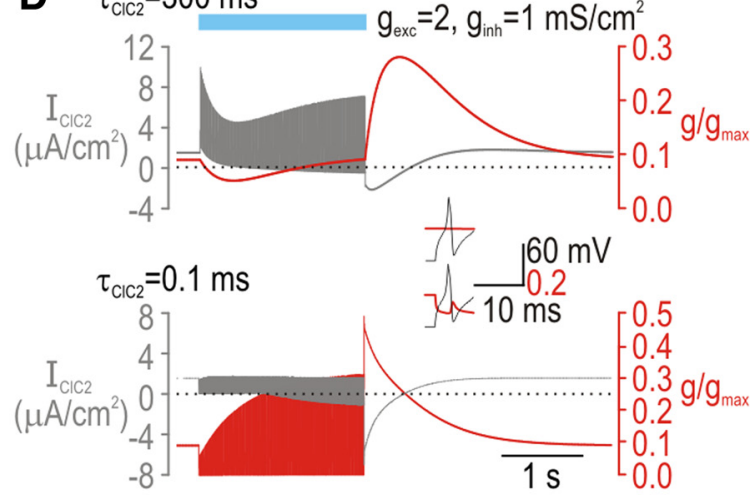

Late during (strong) stimulus

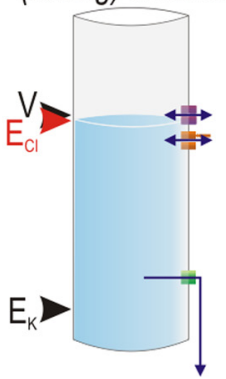

Shortly after (strong) stimulus
$\mathbf{E}$

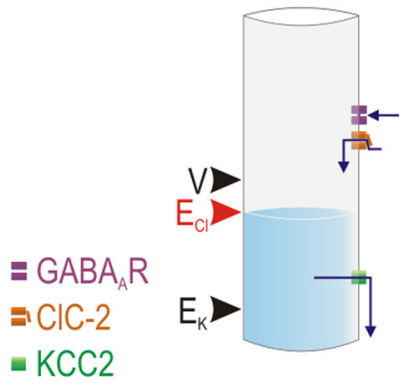

Early during

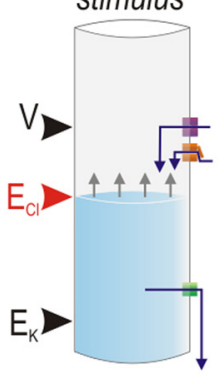

Figure 2. Chloride flux through $\mathrm{CIC}-2$ under physiological conditions (i.e., current clamp, without dialysis, with $\mathrm{KCC} 2) . A, \mathrm{CIC}-2$ produced outward current (i.e., $\mathrm{Cl}^{-}$influx) at all times except during a brief interval (yellow shading) after stimulation, when $\mathrm{Cl}^{-}$driving force was inverted. $\boldsymbol{B}$, Chloride accumulation and driving force (measured $100 \mathrm{~ms}$ after stimulus offset because of CIC- 2 kinetics; see $\boldsymbol{D}$ ) for different strength inputs to soma and dendrites. Dendritic simulations were conducted with and without (difference from former shown in red) active $\mathrm{Na}^{+}$and K+ ${ }^{+}$currents. Inset shows that [Cl $\left.{ }^{-}\right]_{\mathrm{i}}$ kinetics but not steady-state $\left[\mathrm{Cl}^{-}\right]_{\mathrm{i}}$ differ between soma and dendrites. $\mathrm{C}$, Effects of differences in $\left[\mathrm{Cl}^{-}\right]_{\mathrm{i}}$ kinetics when stimulation is brief. In all cases, $\mathrm{Cl}^{-}$efflux via $\mathrm{ClC}-2$ was limited to a brief interval after stimulus offset and paled in comparison with CIC-2-mediated $\mathrm{Cl}^{-}$influx occurring at all other times. $D$, CIC-2 current (gray) and conductance (red) for $\tau_{\mathrm{CIC} 2}=300 \mathrm{~ms}$ (top panel) and $\tau_{\mathrm{CIC} 2}=0.1 \mathrm{~ms}$, i.e., nominally instantaneous (bottom panel). For $\tau_{\mathrm{CIC}}=300 \mathrm{~ms}$, (IC-2 was weakly active at resting Vand deactivated slowly during depolarization; $I_{\mathrm{CIC} 2}$ changed rapidly because of fluctuations in driving force during spikes, not because of rapid changes in conductance. Slow changes in activation reflectactivation kinetics plus slow trends in average $V$ and $E_{\mathrm{Cl}}$. For $\tau_{\mathrm{CIC} 2}=0.1 \mathrm{~ms}$, $\mathrm{ClC}-2$ was still weakly active at resting $V$ but rapidly deactivated during spikes. Insets show enlarged view of first spike. $\boldsymbol{E}$, Summary of factors affecting $\mathrm{Cl}^{-}$flux at different times relative to stimulation. 
fected $\mathrm{Cl}^{-}$extrusion by $\mathrm{ClC}-2$, it did not affect extrusion by KCC2 since KCC2 driving force (calculated as $E_{\mathrm{K}}-E_{\mathrm{Cl}}$ ) was unaffected. Unlike ClC-2, KCC2 mitigated total $\mathrm{Cl}^{-}$accumulation because of the direction of its driving force and its persistent activation during depolarization. These data argue that by harnessing the transmembrane $\mathrm{K}^{+}$gradient, cotransporter-mediated $\mathrm{Cl}^{-}$ extrusion occurs via a stronger and more stable driving force than channel-mediated $\mathrm{Cl}^{-}$extrusion. Nevertheless, these data are still consistent with $\mathrm{Cl}^{-}$efflux via $\mathrm{ClC}-2$ (Fig. 1E).

\section{Direction of $\mathrm{Cl}^{-}$flux in current-clamp simulations}

Current-clamp simulations in the same model revealed a fundamentally different picture from that described above. After strong $\mathrm{Cl}^{-}$loading, $\mathrm{Cl}^{-}$efflux via $\mathrm{ClC}-2$ occurred only during a brief interval after stimulus offset (Fig. 2A). This interval corresponds to when $\mathrm{Cl}^{-}$driving force was inverted, and was absent for stimuli causing less $\mathrm{Cl}^{-}$accumulation (Fig. 2B) or if stimulus offset was more gradual (data not shown). In fact, $\mathrm{ClC}-2$ allowed $\mathrm{Cl}^{-}$ influx at rest, during stimulation, and even for much of the time after stimulation when $\left[\mathrm{Cl}^{-}\right]_{\mathrm{i}}$ was elevated above resting levels. This pattern was observed in soma and dendrites; the only notable difference was that $\left[\mathrm{Cl}^{-}\right]_{\mathrm{i}} \mathrm{ki}-$ netics are faster in dendrites, which allows greater $\mathrm{Cl}^{-}$accumulation during brief stimulation (Fig. 2C) but can also prevent ClC-2 channels from having enough time to activate before $\left[\mathrm{Cl}^{-}\right]_{\mathrm{i}}$ is reduced via other mechanisms (Fig. $2 B$; see also below). Note in Figure $2 B$ that $\left[\mathrm{Cl}^{-}\right]_{\mathrm{i}}$ did not exceed $\sim 20 \mathrm{~mm}$ when KCC2 was intact, even during strong stimulation - this defines the upper limit of physiological $\left[\mathrm{Cl}^{-}\right]_{\mathrm{i}}$. These results highlight the importance of driving force and contradict the prevailing view that inward rectification prevents $\mathrm{ClC}-2$ from mediating $\mathrm{Cl}^{-}$ influx.

To investigate why inward rectification fails to prevent $\mathrm{Cl}^{-}$ influx, we compared normal slow-gated $\mathrm{ClC}-2$ conductance $\left[\tau_{\mathrm{ClC} 2}=300 \mathrm{~ms}\right.$ based on Staley (1994) $]$ with a hypothetical, instantaneously gated ClC-2 conductance (Fig. $2 D$ ). For $\tau_{\mathrm{ClC} 2}$ $=300 \mathrm{~ms}, \mathrm{ClC}-2$ produced substantial outward current before deactivation developed following onset of a depolarizing event. In fact, deactivation was negligible during fast events like action potentials (see Fig. 2D, inset) and EPSPs (see below). For deactivation to occur on this faster time scale, $\tau_{\mathrm{ClC} 2}$ must be reduced by $>10 \times$. Furthermore, regardless of gating kinetics, inward rectification was incomplete at rest as evidenced by nonzero resting ClC-2 conductance. Thus, inward rectification of ClC-2 is neither instantaneous nor complete. This, coupled with driving force conducive to $\mathrm{Cl}^{-}$influx, means that ClC-2 normally produces outward current via $\mathrm{Cl}^{-}$ influx. ClC-2 parameters were equivalent in voltage-clamp and current-clamp simulations, which points to testing conditions as the basis for the difference in direction of $\mathrm{Cl}^{-}$flux (Fig. 2E).

A
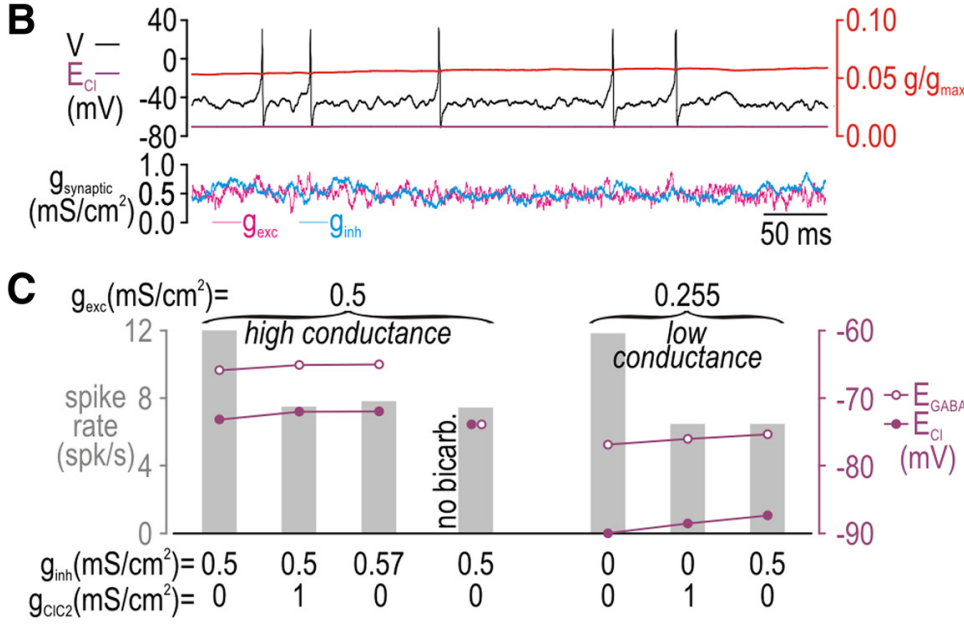

Figure 3. Effects of $\mathrm{CIC}-2$ on neuronal excitability. $A$, Instantaneous firing rate (= reciprocal of interspike intervals) remained constant in model without $\mathrm{ClC}-2$ but increased in parallel with $\mathrm{CIC}-2$ deactivation in model with $\mathrm{CIC}-2$. This demonstrates that spiking is reduced by CIC-2-mediated outward current. Constant current injection (cyan bar) was applied instead of conductancewith top panel of Fig. 2D). B, To investigate how (IC-2 affects spiking driven by synaptic input, a model neuron was bombarded by tory and inhibitory synaptic input; $\tau_{\text {exc }}=2 \mathrm{~ms}, \tau_{\text {inh }}=10 \mathrm{~ms}, \mu_{\text {exc }}=\mu_{\text {inh }}=0.5 \mathrm{mS} / \mathrm{cm}^{2}, \sigma_{\text {exc }}=\sigma_{\text {inh }}=0.1 \mathrm{mS} / \mathrm{cm}^{2}$ rates, $E_{C}$ and $E_{\text {a }}$ (which accounts forbicarbonate effluxthrough $G_{A B A} \mathrm{R}$ ) for differentcombinations of $g$. parameters as in $\boldsymbol{B}$. In the high-conductance state, strong inhibition is balanced by strong excitation and causes a large depolarizing shift in $E_{\mathrm{CI}}$ and $E_{\mathrm{GAB} A}$; in the low-conductance state, $g_{\mathrm{exc}}$ was reduced to give the same baseline spike rate.

\section{Effects of ClC-2 current on neuronal excitability}

We predicted that $\mathrm{ClC}-2$ should directly reduce neuronal spiking if the current is indeed outward. To test this, we compared firing rates in models with and without $\mathrm{ClC}-2$ in response to constant current injection (Fig. $3 A$ ) and to synaptic-like input (Fig. $3 B, C$ ). Under all conditions (including high- and low-conductance states with different $E_{\mathrm{Cl}}$ values), ClC-2 reduced spiking. Firing rate reduction was especially pronounced for spiking driven by synaptic input because EPSPs were sufficiently short that they provoked little if any deactivation of ClC-2 (see Fig. 3B).

To test whether ClC-2 reduces spiking in real neurons, we used dynamic clamp to insert virtual $g_{\mathrm{ClC} 2}$ into CA1 pyramidal neurons recorded in vitro and stimulated with virtual synaptic input. As predicted, adding virtual $g_{\mathrm{ClC} 2}$ reduced spiking with native ClC-2 channels intact (Fig. 4A) or blocked (Fig. 4B). Furthermore, because $\mathrm{ClC}-2$ and synaptic currents implemented by dynamic clamp are not mediated by transmembrane $\mathrm{Cl}^{-}$flux and because $E_{\mathrm{Cl}}$ and $E_{\mathrm{GABA}}$ are held constant, our experiments demonstrate that $I_{\mathrm{ClC}_{2}}$ can regulate neuronal excitability directly, rather than acting indirectly through modulation of $\mathrm{GABA}_{\mathrm{A}} \mathrm{R}$-mediated inhibition.

\section{Discussion}

Despite having rectification properties that suggest they act as $\mathrm{Cl}^{-}$exit valves, our results show that $\mathrm{ClC}-2$ channels normally 
A

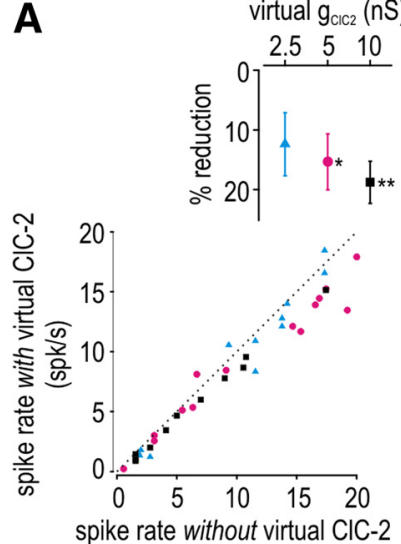

(spk/s)
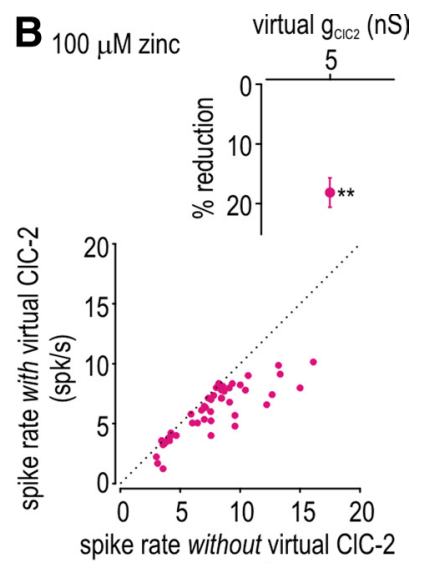

(spk/s)

Figure 4. Effects of virtual $\mathrm{CIC}-2$ conductance in $\mathrm{CA} 1$ pyramidal neurons. $A$, Neurons were stimulated with virtual synaptic inputs applied by dynamic clamp. With native CIC-2 channels intact, stimulus parameters were varied slightly to achieve a range of firing rates in each cell $(n=4)$. In interleaved trials, virtual CIC-2 conductance (3 different $g_{\max }$ values with at least 2 values tested per cell) was inserted by dynamic clamp. Plots show spike rates with versus without virtual $\mathrm{CIC}-2$ based on comparison of consecutive trials. Points below dotted line indicate reduction of firing rate by $\mathrm{ClC}-2$. Observed distribution was significantly different from expected; $\chi^{2}=26.0, p<0.001$. Inset shows mean ( \pm SEM) reduction in firing rate. Paired $t$

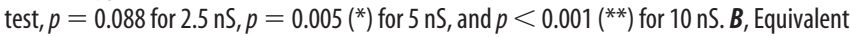
experiments $(n=6)$ repeated with native CIC- 2 channels blocked by $100 \mu \mathrm{m}$ zinc. $\chi^{2}=27.0$, $p<0.001$. Paired $t$ test, $p<0.001\left({ }^{*}\right)$. Mean reduction caused by virtual CIC -2 was not significantly different with versus without native $\mathrm{CIC}-2 ; t$ test, $p=0.60$.

leak $\mathrm{Cl}^{-}$into neurons. This occurs because $\mathrm{Cl}^{-}$driving force is almost always against the valve's preferred direction and because ClC-2 rectification has slow kinetics and is incomplete at rest. Therefore, rather than acting primarily to reduce $\left[\mathrm{Cl}^{-}\right]_{\mathrm{i}}$ and replenish the transmembrane $\mathrm{Cl}^{-}$gradient for the benefit of $\mathrm{GABA}_{\mathrm{A}} \mathrm{R}$-mediated synaptic inhibition, our data demonstrate that $\mathrm{ClC}-2$ functions under physiological conditions as a leak conductance that directly reduces neuronal excitability.

A role in regulating neuronal excitability is consistent with data showing that $\mathrm{ClC}-2$ reduces input resistance (Madison et al., 1986; Rinke et al., 2010). However, ClC-2 cannot simultaneously provide $\mathrm{Cl}^{-}$efflux pathway and shunt depolarizing input, since the latter requires $\mathrm{ClC}-2$ to produce an outward current via $\mathrm{Cl}^{-}$ influx. Shunting still requires $\mathrm{Cl}^{-}$-mediated outward current to counterbalance cation-mediated inward current (Price et al., 2009) - it is not true that cations simply leak out open $\mathrm{Cl}^{-}$channels, contrary to what "shunting" might suggest.

Disambiguating whether ClC-2 affects neuronal excitability directly or by modulating the strength of synaptic inhibition is important. For example, consider pathological conditions associated with $\mathrm{Cl}^{-}$dysregulation (e.g., by KCC2 downregulation): if ClC-2 regulates $\left[\mathrm{Cl}^{-}\right]_{\mathrm{i}}$, increased $\mathrm{ClC}-2$ activity could compensate for reduced KCC2 activity and mitigate disinhibition; in contrast, if ClC-2 regulates excitability directly, ClC-2 activity would exacerbate $\mathrm{Cl}^{-}$accumulation when KCC2 is reduced. Interestingly, a role for ClC-2 in epilepsy based on human data has been suggested but is contentious (Niemeyer et al., 2010), and ClC-2-deficient mice do not have an obvious seizure phenotype (Bösl et al., 2001; Blanz et al., 2007), although subtle effects have been noted (Cortez et al., 2010). It is also notable that ClC-2 itself is subject to significant modulation (Madison et al., 1986; Staley, 1994).

In conclusion, our results contradict the prevailing view that ClC-2 constitutes a $\mathrm{Cl}^{-}$efflux pathway. Although our model can reproduce voltage-clamp data that are the basis for ascribing this role to $\mathrm{ClC}-2$, the same model tested under physiological conditions

clearly shows that ClC-2 normally leaks $\mathrm{Cl}^{-}$into the cell, thus regulating neuronal excitability directly. Reminiscent of issues regarding $\mathrm{GABA}_{\mathrm{A}} \mathrm{R}$ function (e.g.) is $\mathrm{GABA}_{\mathrm{A}} \mathrm{R}$ input inhibitory or excitatory at different developmental stages, in different disease states, in different cellular compartments?), our results emphasize that driving force must be carefully considered when inferring channel function.

\section{References}

Blaesse P, Airaksinen MS, Rivera C, Kaila K (2009) Cation-chloride cotransporters and neuronal function. Neuron 61:820-838.

Blanz J, Schweizer M, Auberson M, Maier H, Muenscher A, Hübner CA, Jentsch TJ (2007) Leukoencephalopathy upon disruption of the chloride channel ClC-2. J Neurosci 27:6581-6589.

Bösl MR, Stein V, Hübner C, Zdebik AA, Jordt SE, Mukhopadhyay AK, Davidoff MS, Holstein AF, Jentsch TJ (2001) Male germ cells and photoreceptors, both dependent on close cell-cell interactions, degenerate upon $\mathrm{ClC}-2 \mathrm{Cl}^{-}$channel disruption. EMBO J 20:1289-1299.

Cortez MA, Li C, Whitehead SN, Dhani SU, D’Antonio C, Huan LJ, Bennett SA, Snead OC 3rd, Bear CE (2010) Disruption of ClC-2 expression is associated with progressive neurodegeneration in aging mice. Neuroscience 167:154-162.

De Koninck Y (2007) Altered chloride homeostasis in neurological disorders: a new target. Curr Opin Pharmacol 7:93-99.

Doyon N, Prescott SA, Castonguay A, Godin AG, Kröger H, De Koninck Y (2011) Efficacy of synaptic inhibition depends on multiple dynamically interacting mechanisms implicated in chloride homeostasis. PLoS Comput Biol 7:e1002149.

Ermentrout B (2002) Simulating, analyzing, and animating dynamical systems: a guide to XPPAUT for researchers and students. Philadelphia: SIAM.

Földy C, Lee SH, Morgan RJ, Soltesz I (2010) Regulation of fast-spiking basket cell synapses by the chloride channel ClC-2. Nat Neurosci 13:1047-1049.

Kahle KT, Staley KJ, Nahed BV, Gamba G, Hebert SC, Lifton RP, Mount DB (2008) Roles of the cation-chloride cotransporters in neurological disease. Nat Clin Pract Neurol 4:490-503.

Madison DV, Malenka RC, Nicoll RA (1986) Phorbol esters block a voltagesensitive chloride current in hippocampal pyramidal cells. Nature 321:695-697.

Niemeyer MI, Cid LP, Sepúlveda FV, Blanz J, Auberson M, Jentsch TJ (2010) No evidence for a role of CLCN2 variants in idiopathic generalized epilepsy. Nat Genet 42:3.

Payne JA, Rivera C, Voipio J, Kaila K (2003) Cation-chloride co-transporters in neuronal communication, development and trauma. Trends Neurosci 26:199-206.

Prescott SA, De Koninck Y (2009) Impact of background synaptic activity on neuronal response properties revealed by stepwise replication of in vivo-like conditions in vitro. In: The dynamic clamp: from principles to applications (Destexhe A, Bal T, eds), pp 89-114. New York: Springer.

Prescott SA, Ratté S, De Koninck Y, Sejnowski TJ (2006) Nonlinear interaction between shunting and adaptation controls a switch between integration and coincidence detection in pyramidal neurons. J Neurosci 26:9084-9097.

Prescott SA, De Koninck Y, Sejnowski TJ (2008) Biophysical basis for three distinct dynamical mechanisms of action potential initiation. PLoS Comput Biol 4:e1000198.

Price TJ, Cervero F, Gold MS, Hammond DL, Prescott SA (2009) Chloride regulation in the pain pathway. Brain Res Rev 60:149-170.

Rinke I, Artmann J, Stein V (2010) ClC-2 voltage-gated channels constitute part of the background conductance and assist chloride extrusion. J Neurosci 30:4776-4786.

Smart TG (2010) Handling accumulated internal $\mathrm{Cl}^{-}$at inhibitory synapses. Nat Neurosci 13:1043-1044.

Staley K (1994) The role of an inwardly rectifying chloride conductance in postsynaptic inhibition. J Neurophysiol 72:273-284.

Staley KJ, Proctor WR (1999) Modulation of mammalian dendritic GABA(A) receptor function by the kinetics of $\mathrm{Cl}^{-}$and $\mathrm{HCO}_{3}{ }^{-}$transport. J Physiol 519:693-712.

Staley KJ, Soldo BL, Proctor WR (1995) Ionic mechanisms of neuronal excitation by inhibitory $\mathrm{GABA}_{\mathrm{A}}$ receptors. Science 269:977-981.

Thompson SM, Gähwiler BH (1989) Activity-dependent disinhibition. I. Repetitive stimulation reduces IPSP driving force and conductance in the hippocampus in vitro. J Neurophysiol 61:501-511.

Uhlenbeck GE, Ornstein LS (1930) On the theory of Brownian motion. Phys Rev 36:823-841. 